\title{
Lucky Reply Effect
}

\section{How a Company's Online Replies to Consumers' Online Comments Affect Consumers' Predictions of Randomly Determined Associated Rewards}

\author{
Ming Chen, Nanjing University of Finance and Economics, China \\ Yidan Huang, Huaqiao University, China \\ Shih-Heng Yu, National United University, Taiwan \\ Chia-Huei Wu, Minghsin University of Science Technology, Taiwan
}

\begin{abstract}
As social media has developed, online interaction between consumers and companies has increased rapidly. This research explores how companies' replies to consumers' past online comments affect consumers' predictions of their chances of winning randomly determined associated rewards (e.g., a random drawing). The results of two studies show that consumers who left positive comments (encouragement/appreciation) and then received a reply from the company predicted a higher likelihood of winning a random drawing than those whose comments did not receive company replies. Both the boundary and the underlying mechanism of the effect are discussed in the research. The present research contributes to the literature on companies' online reply patterns by linking their online replies with consumer predictions concerning randomly determined rewards, extends consumer efforts from offline purchases to online comments, and provides insights into the differences between consumer predictions regarding traditional offline promotional events and online promotional events.
\end{abstract}

\section{KEYWORDS}

Online Comment, Online Reply, Randomly Determined, Valuable Efforts

\section{INTRODUCTION}

With the development of new information and communication technologies—and in particular, with the development of the Internet and social networks-consumers' consumption habits have changed by virtue of having new channels through which to search for, assess, choose, and buy goods and services (Alves, Fernandes, \& Raposo, 2016). To adapt to this changing market, companies must develop appropriate and effective Internet marketing tactics. Social media can efficiently bring consumers and companies closer to one another not only by providing companies with the opportunity to communicate with consumers through various social networks but also by allowing customers to conveniently leave negative or positive comments (complaints or appreciation) with companies (Kelly, Kerr, \& Drennan, 2010). It is therefore not surprising that large companies, small and medium-sized enterprises, individuals, and even presidential candidates are effectively exploiting social media as a tool for communication and promotion (Riu, 2015). In addition, traditional marketing strategies are increasingly being employed by means of social media. For example, Hungry Jack's in Australia 
promotes its business with a mobile app named "Hungry Jack's Shake \& Win." Consumers can win free coupons for Hungry Jack's by shaking their mobile device and checking in with their Facebook account.

Social media provide consumers a means of communicating with one another and companies (Floreddu \& Cabiddu, 2016). Many companies in China promote their products and communicate with consumers through Weibo, which functions in China as the equivalent of Twitter in the U.S. One propaganda method frequently employed by companies on Weibo is called "comment, forwarding, and drawing". When companies promote new products, services and/or events, they introduce their advertising through Weibo and inform their consumers, "Comment and forward this post, and you will be entered into a random drawing to win rewards!" The speed at which the advertisement spreads accelerates as a result of this promotional method. Do consumers predict that they have the same likelihood to win a prize? Would the number of consumers' past comments influence their predictions? What would a company's replies on social media mean for consumers? Would these replies influence consumers' perceptions? The present research addresses these questions.

This research examines whether companies' responses affect consumers' perceptions and judgements by assessing consumers' predictions concerning randomly determined rewards in a drawing as part of an Internet promotion, even when the drawing is explicitly identified as random. Although the comments left by consumers on social media are typically either positive or negative, we consider only the positive comments in this research. When the comments were positive (encouragement/ appreciation), consumers who received replies from the company felt they were more likely to win the drawing no matter how many comments they left previously. Consumers did not believe they would win the drawing when the company replied only to their comments because they believed their efforts (e.g., positive comments) were more valuable to the company than others' efforts. The present research contributes to the literature on companies' online reply patterns by linking their online replies with consumers' predictions of winning randomly determined rewards, promotes consumers' involvement from making offline purchases to posting online comments, and provides insights into the differences between consumers' predictions regarding traditional offline promotional events and online promotional events. In addition, the present research provides marketers with deep insights into consumers' psychology and some suggestions for drawing promotion.

\section{THEORETICAL BACKGROUND}

\subsection{Effect of Online Comments}

Traditional media such as television and newspapers are considered low-interactive media because audiences can only receive information passively and cannot provide feedback (Schultz, 2000). However, the emergence of the Internet has significantly altered these methods of communication. In contrast to traditional media, online media allow individuals to express their opinions quickly and easily, such as through online comments. As online consumers' comments are often readily visible to others; these comments may be viewed as representing public opinion, particularly in direct assessments of the public climate (Lee \& Jang, 2010). Meanwhile, consumers are more likely to be influenced by inferences they make about public opinion based on the comments of others (Li \& Feng, 2015). For example, Lee and Jang (2010) found online comments on online news exerted a greater influence on people's perspectives than the opinions expressed in the news itself. Thus, on the one hand, consumer complaints can provide an opportunity for companies to understand the root causes of consumer problems and to gain competitive advantage as the result of improvements made due to complaint-related problems (Yilmaz, Varnali, \& Kasnakoglu, 2016). On the other hand, comments communicating encouragement or appreciation are always welcomed by a company. Positive comments on social media can enhance brand attitudes and significantly influence consumers' purchasing decisions (Xue \& Phelps, 2004; Lee \& Youn, 2009). 
Given the crucial role of online comments in Internet marketing, consumers also use comments to express their emotions and opinions about the company, such as by using the "Like" button. Gerlitz and Helmond (2013) argued that people use "social buttons" (e.g., share, recommend, like, post, vote, and bookmark) on social media to present their opinions clearly and easily. For example, Nike's Facebook has more than 32 million "likes". In these cases, fans of Nike signal their affection using online comments and "social buttons". From consumers' perspectives, leaving comments and clicking the "like" button are ways of supporting their favorite companies. Meanwhile, companies with many "likes" and comments on their social media pages can build on this popularity to increase sales, to increase their returns on investments, to spread information about their brands, and to enhance their brand reputations (Abedin, 2016; Kozinets, Valck, Wojnicki, \& Wilner, 2010; Yu, Duan, \& Cao, 2013; Kumar, Bhaskaran, Mirchandani, \& Shah, 2013). The "2018 Alipay Chinese Koi" is one of the most successful examples of social media promotion. At the beginning of the Chinese National Day Golden Week Holiday in 2018, Alipay organized a marketing activity of in which all a consumer needed to do was retweet a microblog posted by Alipay to be entered into the drawing pool. At the end of the holiday, only one person was randomly chosen as the "Chinese Koi" and won an incredible list of prizes provided by more than 200 of Alipay's partners. Finally, more than 3 million people had commented, retweeted and joined the "Chinese Koi" lucky draw.

Consumer comments are also a type of electronic word-of-mouth (eWOM), which is defined as entailing any positive or negative comments made visible to others via the Internet from potential, actual, or former customers regarding a product or company (Hennig-Thurau, Gwinner, Walsh, \& Gremler, 2004). Numerous studies have demonstrated that eWOM plays a crucial role in influencing consumer behavior (Bronner, \& de Hoog, 2011; Chen \& Xie, 2008; King, Racherla, \& Bush, 2014; Chen, Zhang, \& Chen, 2018; Li \& Wang, 2018; Subramaniyaswamy, Logesh, Abejith, Umasankar, \& Umamakeswari, 2017). Thus, from both consumers' and the company's perspectives, leaving comments on a company's social media page is an effective means of supporting the company and of contributing to its marketing efforts.

\subsection{Companies' Replies and Consumers' Beliefs}

Consumers use social media to communicate with companies, and vice versa. Due to the ease of accessing social media, many companies receive numerous comments on their social media feeds. However, it is difficult for companies to reply to such comments individually. Mattila, Andreau, Hanks, and Kim (2013) find consumers feel no significant differences between a company's automated reply and no reply at all. Therefore, in the real world, companies typically reply to a limited number of comments they deem representative of all comments. For example, a post tweeted by Xiaomi company has received more than 300 comments, but only 2 comments have received replies from the company. Imagine a situation in which you are a fan of Nike and you leave an encouraging comment on a post that is an advertisement for Nike's new shoes on Facebook. Including yours, only 10 comments out of more than 1000 comments receive replies from Nike. Would you then believe your support and efforts were more valuable to Nike than others' efforts? Would you believe you might receive special treatment from Nike over others who also left comments but did not receive a reply precisely because your support and efforts were more valuable to Nike?

Prior research has examined the association between consumer's efforts and receiving rewards. For example, Jiang, Hoegg, and Dahl (2013) find that the association between consumers' efforts with regard to a company through the consumer's past purchases and expectation of rewards is so strong that consumers feel less satisfied with a company when they do not receive special treatment, even when they are receiving a desirable perk, such as a free upgrade. In addition, Reczek et al. (2014) proposed that consumers' past purchases would prompt a feeling of deservingness (because of past purchases) that would translate into a higher likelihood of receiving rewards from the company than that of other consumers. According to equity theory, consumers believe their input should receive commensurate responses and output from companies (Adam, 1965). Consumers' experiences of 
being rewarded for their prior efforts provide expectations their future efforts should be compensated by other rewards. Several previous studies based on the notion of dual entitlement and fairness have proposed a similar argument, i.e., that consumers expect to receive certain rewards from companies as payback for their efforts (Aurigemma \& Mattson, 2018; Haws \& Bearden 2006; Reczek, Haws, \& Summers, 2014; van den Bos, Lind, Vermunt, \& Wilke, 1997). Thus, when consumers are asked to predict their likelihood of receiving a reward from a company, they naturally regard efforts as a criterion. In other word, consumers' efforts would influence their predictions of gaining rewards by the company because of the dual entitlement principle.

However, unlike consumers' unilaterally subjective perspective in the case of traditional offline consumption, namely, their efforts as evidenced by past purchases merits special treatment from the company, consumers who extend their efforts through online comments may receive replies from the company that can be regarded as a bilateral interaction with companies. We suggest replies from companies would be perceived by consumers as an objective signal that their efforts and support are more valuable to the company than others' efforts regardless of how many comments they left previously. Moreover, a company's reply can strengthen consumers' beliefs that they will be treated uniquely (based on their valuable efforts) and thus may influence their predictions regarding the likelihood of receiving rewards from the company as compensation, regardless of whether the rewards are allocated randomly or based on the consumers' actions (Feather, McKee, \& Bekker 2011; Reczek et al., 2014). By contrast, consumers who frequently leave comments on a company's social media page but do not receive any replies would not have the same feeling that their efforts are more valuable than others' efforts because of the sheer volume of comments on the company's social media page. Although these consumers make efforts to communicate with the company, if they do not receive a company reply, they do not typically believe their efforts are more valuable to the company than others' efforts. Thus, they would not predict they are more likely than other customers to receive rewards. We argue consumers' beliefs their efforts are more valuable to the company than others' efforts even in more extreme situations, such as random draws, will influence consumers' predictions and judgements. Consumers would regard the random draw as a type of repayment for their efforts and support. Thus, we propose the following hypothesis:

H1: Consumers' predictions of winning a random reward would be influenced by whether their comments are replied to by the company, regardless of the number of comments they left previously.

H2: This lucky reply effect is mediated by consumers' beliefs their efforts are more valuable to the company than others' efforts.

As we argued before, consumers' beliefs that their efforts are more valuable to the company than others' efforts play a crucial role in this effect. However, consumers whose comments receive company replies would feel their efforts are more valuable only than those the "average" consumers or other consumers whose comments do not receive company replies but not relative to other consumers whose comments are also replied by the company. Hence, if the company is "industrious", which means the majority of consumers' comments have received company replies, consumers whose comments receive company replies would not have the feeling their efforts are more valuable than others' efforts because the "average" consumers' comments receive company replies. As a result, they would not predict a higher likelihood of winning the reward. Similar results were found by Reczek et al. (2014) in their study 5. They argued that if consumers do not perceive that they have invested more effort than others, they will not feel that they have a higher likelihood to win random outcomes. Thus, we propose the following hypothesis:

H3: This lucky reply effect occurs only when a few consumers' comments receive company replies and does not occur when most consumers' comments receive company replies. 
A theoretical model including an overview of the hypotheses and showing in which studies they are investigated is provided in Figure 1.

Figure 1. Research framework

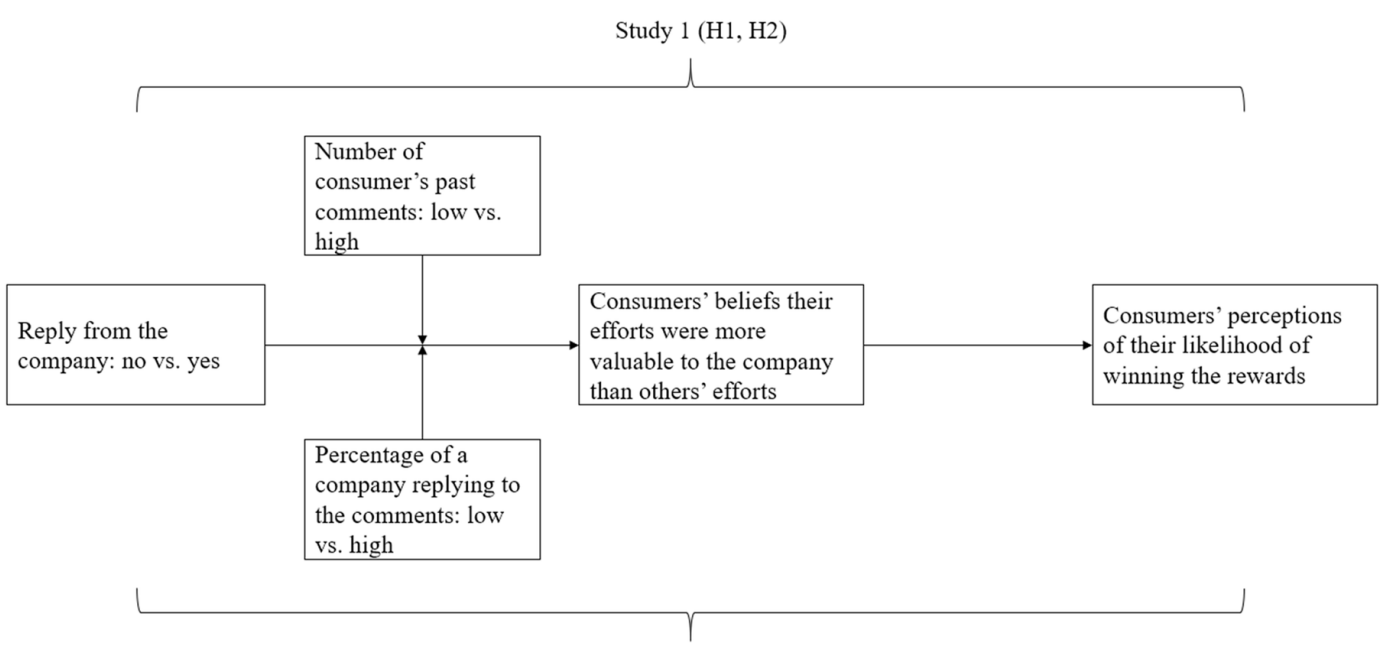

Study 2 (H2, H3)

\section{STUDY 1}

Study 1 tests whether a company replies influences consumers' predictions regarding randomly determined rewards, and the mediating factor is the consumers' beliefs their efforts are more valuable to the company than others' efforts.

\subsection{Method}

One hundred twenty students (age range: $18-28$ years, $M_{\text {age }}=22.68, \mathrm{SD}=2.59,33.3 \%$ male, $86.7 \%$ participants used Facebook daily, 12.5\% participants used Facebook 4-6 times weekly, and 0.8\% participants used Facebook fewer than 4 times weekly) from different departments of a large public university in Taiwan participated in the study in exchange for course credit. Participants were randomly assigned to one of 4 conditions in a 2 (number of consumer's past comments: low vs. high) x 2 (reply from the company: no vs. yes) between-subjects study. All participants were asked to read and imagine a scenario in which, "A clothing company named ACL holds a random drawing on Facebook to celebrate its anniversary. People who forward this post will have the chance to win a coupon worth NT\$ 1000. You forward this post." We manipulate the conditions of high (low) numbers of comments and with (without) reply in the following manner, "There are many comments below each post on ACL's Facebook page, but only a few comments actually receive replies from the company. You left many (a few) positive comments on ACL's Facebook page last month, and three (none) of them received replies from the company".

To verify the manipulation of the number of consumer's past comments, participants used a 7-point scale $(1=$ strongly disagree, $7=$ strongly agree $)$ to indicate their agreement with the following statement: "I left numerous comments on ACL's Facebook page last month." We also checked the manipulation for the reply from the company with the following statement on a 7-point scale: "My positive comments received replies from the company." 
Participants were then asked to indicate their chances of winning the coupon on a 7-point scale, in response to the following statements $(\alpha=0.82)$ : "I am more likely to win the coupon compared with other consumers in the random drawing," and "I am more likely to win the NT\$ 1000 coupon." Moreover, because we predicted that consumers' beliefs their efforts are more valuable to the company than others' efforts would be the influencing factor on consumers' predictions, we also asked participants to use the same 7-point scale to rate their agreement with the following statements $(\alpha=0.81)$ : "My efforts are more valuable to the ACL company than others' efforts," and "My efforts contribute more to the ACL company than others' efforts."

\subsection{Results and Discussion}

The results of the manipulation check on the number of consumer's past comments showed that participants in the large number of comments condition $(M=6.05, S D=0.79)$ reported they left more comments on company's Facebook page last month than participants in the low number of comments condition $(M=2.17, S D=0.72, t(1,118)=28.19, p<0.01)$. The manipulation check also revealed a significant difference between the participants in the without receiving company reply condition $(M=1.70, S D=0.67)$ and those in the receiving company reply condition $(M=6.17, S D$ $=0.72, t(1,118)=35.22, p<0.01)$.

We conducted a 2 × 2 two-way ANOVA with participants' predictions regarding the likelihood of winning the coupon as the dependent variable. The results (Table 1) revealed a significant main effect for the company's reply $\left(F(1,116)=55.43, p<0.01, \eta^{2}=0.32\right)$. However, no significant main effect was detected either for the number of consumers' past comments $(F(1,116)<1$, NS) or for the other two-way interactions between the number of consumers' past comments and the company's reply $(F(1,116)<1$, NS). The results showed that consumers who received company replies $(M=$ $4.73, \mathrm{SD}=1.05)$ believed they were more likely to win the coupon than those who did not receive company replies $(M=3.35, \mathrm{SD}=0.95)$.

\section{Table 1. Results of Study 1}

\begin{tabular}{|c|c|c|c|}
\hline $\begin{array}{c}\text { Number of consumer's } \\
\text { past comments }\end{array}$ & Reply from the company & Mean $(M)$ & Standard deviation (SD) \\
\hline \multirow{2}{*}{ High } & Yes & 4.73 & 1.07 \\
\cline { 2 - 4 } & No & 3.30 & 0.84 \\
\hline \multirow{2}{*}{ Low } & Yes & 4.72 & 1.05 \\
\cline { 2 - 4 } & No & 3.40 & 1.07 \\
\hline
\end{tabular}

To determine whether consumers' beliefs that their efforts were more valuable to the company than others' efforts mediated the effects of the company's replies on consumer perceptions of their likelihood of winning the coupon, we conducted a bias-corrected mediation analysis using PROCESS Model 4 (Hayes 2012). The mean indirect effect was positive ( $a \times b=.8944)$, with a $95 \%$ confidence interval (sample $=5000$ ), excluding zero (.6060 to 1.2451), indicating significant mediation by consumers' beliefs their efforts were more valuable to the company than others' efforts, as predicted.

The results of study 1 support $\mathrm{H} 1$ and $\mathrm{H} 2$. These results show that company replies lead consumers to believe their efforts (such as leaving comments and likes) is more valuable to the company than others' efforts, which further prompts them to estimate a higher likelihood of winning the coupon in the drawing as a reward. Therefore, no matter how many comments consumers previously left, receiving company replies leads them to believe their efforts are more valuable and they would have a higher likelihood of winning the reward event prize than other consumers. 


\section{STUDY 2}

Study 2 sought to determine whether the percentage of a company's replies to comments influences consumers' expectations about winning the random drawing jointly with whether a company replies, as mediated by consumers' beliefs their efforts are more valuable to the company than others' efforts.

\subsection{Method}

One hundred twenty students (age range: $18-27$ years, $M_{\text {age }}=21.59, \mathrm{SD}=2.37,23.3 \%$ male, $82.5 \%$ participants used Facebook daily, 13.3\% participants used Facebook 4-6 times weekly, and 4.2\% participants used Facebook fewer than 4 times weekly) from different departments of a large public university in Taiwan participated in this study in exchange for course credit. Participants were randomly assigned to one of 4 conditions in a 2 (percentage of a company replying to the comments: low vs. high) x2 (reply from the company: no vs. yes) between-subjects study. All participants were asked to read and imagine the following scenario: "A clothing company named ACL holds a random drawing on Facebook to celebrate its anniversary. People who forward this post will have the chance to win a coupon worth NT\$ 1000 . You forward this post." We manipulate the conditions of the low (high) percentage of a company replying to the comments, and with (without) reply in the following manner, "There are many comments below each post on ACL's Facebook page, but only a few (and the majority of) comments receive replies from the company. You left several positive comments on ACL's Facebook page last month, and three (none) of them received replies from the company".

To verify the success of manipulating the percentage of a company replying to the comments, participants were asked to indicate their agreement with the following statement on a 7-point scale: "ACL company replies to only a few consumers' comments." In addition, we used the same manipulation check for the reply from the company as we did in study 1 with a 7-point scale.

As with study 1 , participants were asked to indicate their chances of winning the coupon by responding to the two statements presented in study $1(\alpha=0.89)$ and indicating the agreement of the belief their efforts are more valuable to the company than others' efforts $(\alpha=0.83)$ on a 7-point scale.

\subsection{Results and Discussion}

The results of the manipulation check of the percentage of a company replying to the comments showed that participants in the high percentage of a company replying to the comments condition $(M=6.37, S D=0.64)$ reported that the company replies to more comments on its Facebook page last month than participants in the low percentage of a company replying to the comments condition $(M=1.92, S D=0.62, t(1,118)=38.82, p<0.01)$. The manipulation check of the company's reply showed results for participants in the without receiving a company reply condition $(M=2.00, S D$ $=0.76)$ and those in the receiving a company reply condition $(M=6.00, S D=0.86, t(1,118)=$ 26.95, $p<0.01)$.

We conducted a 2 × 2 two-way ANOVA using participants' predictions regarding the likelihood of winning the coupon as the dependent variable. The results revealed the significant main effects of the percentage of a company replying to the comments $\left(F(1,116)=7.98, p<0.01, \eta^{2}=0.05\right)$ and the company's reply $\left(F(1,116)=10.42, p<0.01, \eta^{2}=0.07\right)$. In addition, the results also revealed a significant interaction between the percentage of a company replying to the comments and the company's reply $\left(F(1,116)=16.94, p<0.01, \eta^{2}=0.11\right.$, Figure 2$)$. The results of the planned contrast showed that when consumers' comments did not receive company replies, there was no significant difference on consumers' predictions of winning the coupon between the low percentage of a company replying to the comments condition $(M=3.20, S D=1.12)$ and the high percentage of a company replying to the comments condition $(M=3.45, S D=1.10, F(1,116)<1$, NS). However, when consumers' comments received company replies, consumers in the low percentage of a company replying to the comments condition $(M=4.72, S D=1.20)$ predicted higher likelihoods of winning 
Figure 2. Interaction between the percentage of company replies to the comments and the company's reply on participants' predictions regarding the likelihood of winning the coupon

\section{Figure 1. Interaction between the percentage of a company replying to the comments and the company's reply on participants' predictions regarding the likelihood of winning the coupon}

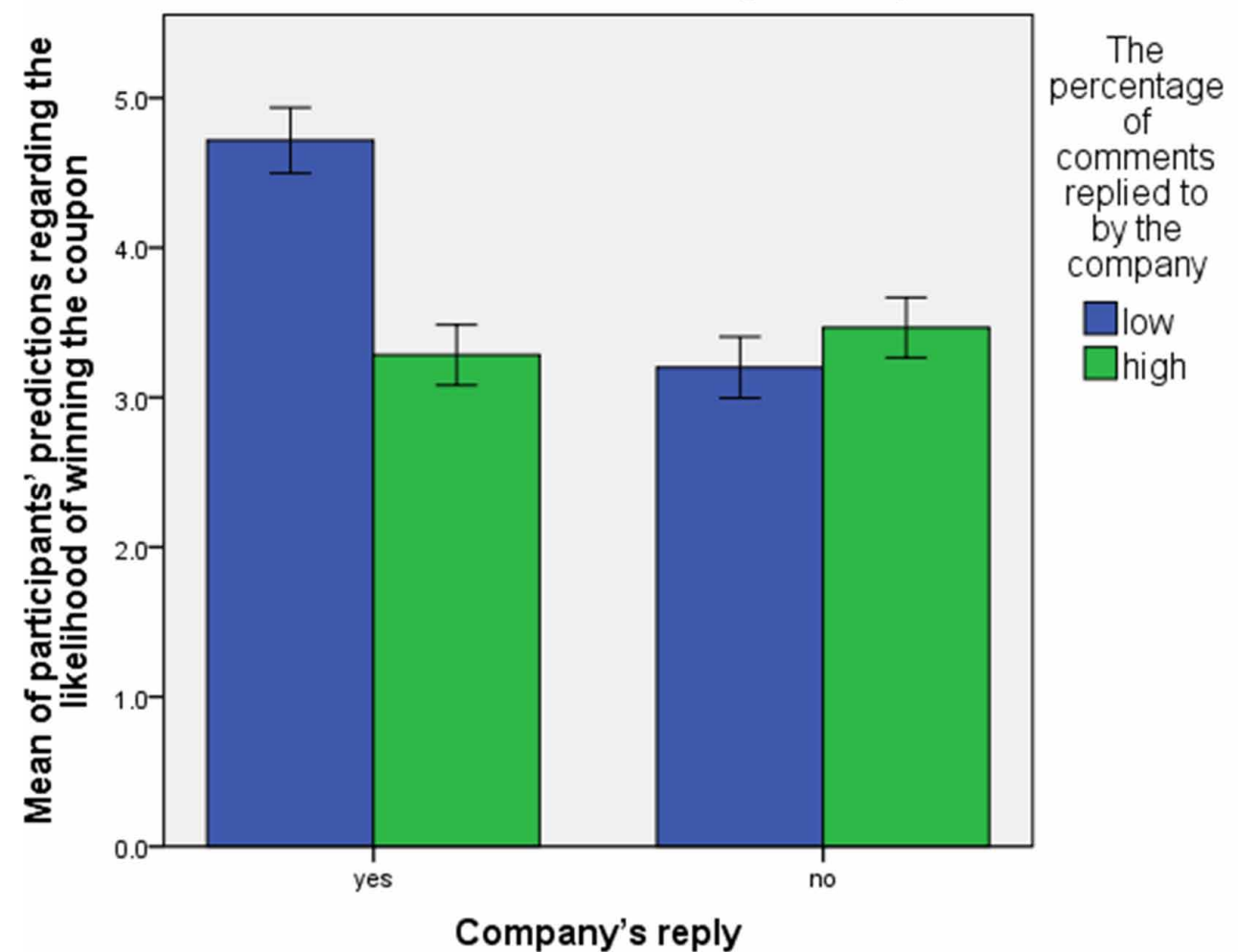

Error bar: +/- $1 \mathrm{SE}$

the coupon than those in the high percentage of a company replying to the comments condition ( $M$ $=3.28, S D=1.10, F(1,116)=24.08, p<0.01$, Figure 2$)$.

As with study 1, we conducted a bias-corrected mediation analysis using PROCESS Model 8 (Hayes 2012) to determine whether consumers' beliefs their efforts were more valuable to the company than others' efforts mediated the effects of the company's replies on consumer perceptions of their likelihood of winning the coupon (as moderated by the percentage of a company replying to the comments). The index of moderated mediation was positive ( $a W \times \mathrm{x} b=.8454)$, with a $95 \%$ confidence interval (sample $=5000$ ), excluding zero (.1856 to 1.4936), indicating significant mediation by the belief their efforts were more valuable to the company than others' efforts, as predicted.

The results of study 2 provide further evidence for $\mathrm{H} 2$ : a company reply will prompt consumers to feel their efforts are more valuable to the company than others' efforts. However, participants will not believe their efforts are more valuable to the company than others' efforts when the company replies to all the consumers' comments. When most consumers' comments receive company replies, consumers whose comments receive company replies would not feel their efforts are more valuable than others' efforts since almost all other consumers' comments receive company replies. Consumers whose comments receive company replies would predict a higher likelihood of winning the coupon only when the company replies to a few consumers' comments, as predicted in $\mathrm{H} 3$. 


\section{GENERAL DISCUSSION}

Increasingly, consumers use social media as a channel through which they can communicate with companies. Online comments are one of the most frequent ways consumers use to encourage and support the companies for which they have an affinity. Whether the comments are appreciative or in the form of a complaint (excluding negative abuse, of course), they reflect consumers' efforts and desires to help the company improve. As a result of the large number of online comments on companies' social media pages, only a few can receive company replies. In the present research, we perform two studies to examine how company replies to consumers' past online comments influence consumers' predictions of the chances of winning randomly determined rewards. The results of the two studies offer evidence that consumers' feelings their past efforts (including online comments and "likes") are more valuable than others' efforts constitute the reason consumers whose past online comments received a company reply predict a higher likelihood of winning a randomly drawn prize. Company replies are regarded by consumers as signals indicating that the company thinks their support and efforts are more valuable than others' efforts, leading them to believe they are more likely to win a drawing as a reward for their efforts. However, the same lucky reply effect occurs only when the company replies to a few consumers' comments.

\subsection{Contributions and Implications}

The present research contributes to the literature in several ways. First, previous studies on companies' online reply patterns are mainly focused on complaint handling (Mattila et al., 2013; Huppertz, 2007) and how to design replies to different consumers (e.g., online support-seeker) (Li \& Feng, 2015). However, the present research links a company's online replies with consumers' perceptions and judgements through assessing consumers' predictions concerning randomly determined rewards. In addition, this research also extends the application of Reczek et al. (2014), which used past purchases to show consumers' loyalty and efforts. We extend the study of consumers' offline purchases to their online comments by identifying the connection between a company's online replies and consumers' beliefs that their efforts are more valuable to the company than others' efforts. Reczek et al. (2014) argued that consumers' past purchases would trigger a feeling of deservingness that would lead to a higher likelihood of receiving rewards from the company than other consumers. In other words, the feeling of deservingness is a subjective thinking triggered by consumers' beliefs that their past purchases contribute more to the company than others' purchases. However, unlike offline past purchases, consumers who leave online comments may receive a reply from the company. Compared with the unilateral subjective feeling of entitlement, consumers who have received company replies, a type of bilateral communication, would then believe their efforts are noticed by the company, which would affect their expectations that they are more likely to win the rewards event. Without company replies, the number of past comments (efforts) cannot influence consumer predictions. Only the comments receiving replies would be regarded as efforts that are more valuable to the company than others consumers' efforts. Moreover, this research also contributes to the promotional events literature. Laporte (2009) classified promotional games into those depending on luck and those depending on skills. Prior research on luck in marketing has focused primarily on the consequences of feeling lucky (Darke, 1997; Jiang, Cho, \& Adaval, 2009). The present research provides another explanation of influences on consumers' perceptions and judgements apart from luck. As a greater variety of promotional methods are used on social media, this research provides new insights regarding the differences between consumers' predictions regarding traditional offline promotional events and online promotional events.

The results of this research will benefit companies. The results show that consumers who always support companies by leaving comments on social media and who receive replies from companies will feel strongly that companies regard their efforts and support as more valuable to the companies than others' efforts. Hence, they will regard promotional activities, even fair activities (random draws), 
as a means of repayment for their support and efforts and will therefore predict a higher likelihood of winning the rewards. For example, the "Chinese Koi" lucky draw was won by an IT engineer whose username was Xin Xiao Dai. Although the majority of the other participants congratulated Xin Xiao Dai, several participants continued to express their dissatisfaction with the drawing result by questioning the fairness of the drawing. Some participants even posted their Alipay bills to show the great efforts they had made previously on Alipay. Similar to the results of our research, they all believed that they should win the rewards. Thus, when companies conduct promotional activities (e.g., lucky draws, coupons), they need to pay more attention to consumers who make more valuable efforts than others. A lucky draw may be a double-edged sword for a company that already has a large number of loyal consumers because these loyal consumers may be unsatisfied with the results of not gaining rewards. On the other hand, a new company can promote its products through a lucky draw that can easily accelerate the spread of advertisement without dissatisfying the consumers since the company does not yet have many loyal consumers. Thus, for "special consumers" who always leave comments and interact with companies on social media, companies can offer a particular promotion to further increase their loyalty and maintain their online participation. A virtuous cycle would result in which companies not only attract more consumers to interact with but also consolidate the loyalty of existing consumers.

\subsection{Limitations and Future Research}

Nonetheless, our study has several limitations and presents potential avenues for further research. The present research focused only on the impacts of positive comments. In real life, negative online comments are even more common than positive comments. Although negative comments may damage a company's reputation, some negative comments can also be used by the company as criteria for future improvement. Hence, a consumer's negative comment (e.g., a complaint about the low battery capacity of a smartphone) that can lead to improvement seems to be more valuable. Would a consumer posting such a comment predict a higher likelihood of winning a randomly drawn prize? In addition, although the sample we used in the present research was comprised of university students from different departments, the sampling method may still have a potential impact on the managerial application of this research. Marketers need to pay attention to the potential impact of the student sample when applying the results of this research due to the different level of familiarity with social media between students and mass consumers. Nevertheless, the present research can still provide valid insights into a cohort that represents a significant target market (i.e., the student market) for companies in online promotions. Our research showed no significant differences regarding the likelihood between high and low numbers of comments when consumers have the same number of replies. However, does no difference in likelihood remain when consumers who leave a few comments with company replies are asked to predict their likelihood of winning the rewards compared with that of others who leave many comments but have only the same number of replies? Furthermore, if the actual reward distribution is random, will consumers have a higher level of disappointment in the long run? Since customer relationship management is conducted over a long period of time, it may be interesting to investigate how the effect of lucky loyalty plays out both in the short run and in the long run. We leave these and other questions for future research to explore. 


\section{REFERENCES}

Abedin, B. (2016). Diffusion of adoption of Facebook for customer relationship management in australia: An exploratory study. Journal of Organizational and End User Computing, 28(1), 56-72. doi:10.4018/ JOEUC.2016010104

Adams, J.S. (1965). Inequity in Social Exchange. In Advances in Experimental Social Psychology, ed. Leonard Berkowitz (pp. 267-299). New York: Academic Press.

Alves, H., Fernandes, C., \& Raposo, M. (2016). Social media marketing: A literature review and implications. Psychology and Marketing, 33(12), 1029-1038. doi:10.1002/mar.20936

Aurigemma, S., \& Mattson, T. (2018). Running with the pack: The impact of middle-status conformity on the post-adoption organizational use of twitter. Journal of Organizational and End User Computing, 30(1), 23-43. doi:10.4018/JOEUC.2018010102

Bronner, F., \& de Hoog, R. (2011). Vacationers and eWOM: Who posts, and why, where, and what? Journal of Travel Research, 50(1), 15-26. doi:10.1177/0047287509355324

Chen, M., Zhang, P., \& Chen, X. (2018). Influence of electronic and traditional word-of-mouth on patients' health-care-seeking behavior. Social Behavior and Personality, 46(5), 759-768. doi:10.2224/sbp.6728

Chen, Y., \& Xie, J. (2008). Online consumer review: Word-of-mouth as a new element of marketing communication mix. Management Science, 54(3), 477-491. doi:10.1287/mnsc.1070.0810

Darke, P. R., \& Freedman, J. L. (1997). The belief in good luck scale. Journal of Research in Personality, 31(4), 486-511. doi:10.1006/jrpe.1997.2197

Feather, N. T., McKee, I. R., \& Bekker, N. (2011). Deservingness and emotions: Testing a structural model that relates discrete emotions to the perceived deservingness of positive or negative outcomes. Motivation and Emotion, 35(1), 1-13. doi:10.1007/s11031-011-9202-4

Floreddu, P. B., \& Cabiddu, F. (2016). Social media communication strategies. Journal of Services Marketing, 30(5), 490-503. doi:10.1108/JSM-01-2015-0036

Gerlitz, C., \& Helmond, A. (2013). The like economy: Social buttons and the data-intensive web. New Media \& Society, 15(8), 1348-1365. doi:10.1177/1461444812472322

Haws, K., \& Bearden, W. (2006). Dynamic pricing and consumer fairness perceptions. The Journal of Consumer Research, 33(3), 304-311. doi:10.1086/508435

Hayes, A. F. (2012). PROCESS: A Versatile Computational Tool for Observed Variable Mediation, Moderation, and Conditional Process Modeling. Retrieved from http://www.afhayes.com/public/process2012.pdf

Hennig-Thurau, T., Gwinner, K. P., Walsh, G., \& Gremler, D. D. (2004). Electronic word-of-mouth via consumeropinion platforms: What motivates consumers to articulate themselves on the internet? Journal of Interactive Marketing, 18(1), 38-52. doi:10.1002/dir.10073

Huppertz, J. W. (2007). Firms' complaint handling policies and consumer complaint voicing. Journal of Consumer Marketing, 24(7), 428-437. doi:10.1108/07363760710834843

Jiang, L., Hoegg, J., \& Dahl, D. W. (2013). Consumer reaction to unearned preferential treatment. The Journal of Consumer Research, 40(3), 412-427. doi:10.1086/670765

Jiang, Y., Cho, A., \& Adaval, R. (2009). The unique consequences of feeling lucky: Implications for consumer behavior. Journal of Consumer Psychology, 19(2), 171-184. doi:10.1016/j.jcps.2009.02.010

Kelly, L., Kerr, G., \& Drennan, J. (2010). Avoidance of advertising in social networking sites: The teenage perspective. Journal of Interactive Advertising, 10(2), 16-27. doi:10.1080/15252019.2010.10722167

King, R. A., Racherla, P., \& Bush, V. D. (2014). What we know and don't know about online word-of-mouth: A review and synthesis of the literature. Journal of Interactive Marketing, 28(3), 167-183. doi:10.1016/j. intmar.2014.02.001 
Kozinets, R. V., Valck, K., \& Wojnicki, A. C. (2010). Networked narratives: Understanding word-of-mouth marketing in online communities. Journal of Marketing, 74(2), 71-89. doi:10.1509/jm.74.2.71

Kumar, V., Bhaskaran, V., Mirchandani, R., \& Shah, M. (2013). Practice prize winner-creating a measurable social media marketing strategy: Increasing the value and ROI of intangibles and tangibles for hokey pokey. Marketing Science, 32(2), 194-212. doi:10.1287/mksc.1120.0768

Laporte, S. (2009). Consumer entry decision in promotional games based on chance: Do the perceived odds of winning matter? Advances in Consumer Research. Association for Consumer Research (U. S.), 36, 1030-1031.

Lee, E., \& Jang, Y. J. (2010). What do others' reactions to news on internet portal sites tell us? effects of presentation format and readers' need for cognition on reality perception. Communication Research, 37(6), 825-846. doi:10.1177/0093650210376189

Lee, M., \& Youn, S. (2009). Electronic word of mouth (eWOM): How eWOM platforms influence consumer product judgement. International Journal of Advertising, 28(3), 473-499. doi:10.2501/S0265048709200709

Li, S., \& Feng, B. (2015). What to say to an online Support-Seeker? the influence of others' responses and Support-Seekers' replies. Human Communication Research, 41(3), 303-326. doi:10.1111/hcre.12055

Li, Y., \& Wang, X. (2018). Seeking health information on social media: A perspective of trust, selfdetermination, and social support. Journal of Organizational and End User Computing, 30(1), 1-22. doi:10.4018/ JOEUC.2018010101

Mattila, A. S., Andreau, L., Hanks, L., \& Kim, E. E. (2013). The impact of cyberostracism on online complaint handling: Is "automatic reply" any better than "no reply"? International Journal of Retail \& Distribution Management, 41(1), 45-60. doi:10.1108/09590551311288166

Reczek, R. W., Haws, K. L., \& Summers, C. A. (2014). Lucky loyalty: The effect of consumer efforts on predictions of randomly determined marketing outcomes. The Journal of Consumer Research, 41(4), 1065-1077. doi:10.1086/678052

Riu, I. A. (2015). Use of social media as a media promotion for small and medium enterprises. Information Management and Business Review, 7(4), 33-41.

Schultz, T. (2000). Mass media and the concept of interactivity: An exploratory study of online forums and reader email. Media Culture \& Society, 22(2), 205-221. doi:10.1177/016344300022002005

Subramaniyaswamy, V., Logesh, R., Abejith, M., Umasankar, S., \& Umamakeswari, A. (2017). Sentiment analysis of tweets for estimating criticality and security of events. Journal of Organizational and End User Computing, 29(4), 51-71. doi:10.4018/JOEUC.2017100103

van den Bos, K., Lind, E. A., Vermunt, R., \& Wilke, H. A. M. (1997). How do I judge my outcome when I do not know the outcome of others? the psychology of the fair process effect. Journal of Personality and Social Psychology, 72(5), 1034-1046. doi:10.1037/0022-3514.72.5.1034 PMID:9150583

Xue, F., \& Phelps, J. E. (2004). Internet-facilitated consumer-to-consumer communication: The moderating role of receiver characteristics. International Journal of Internet Marketing and Advertising, 1(2), 121-136. doi:10.1504/IJIMA.2004.004016

Yilmaz, C., Varnali, K., \& Kasnakoglu, B. T. (2016). How do firms benefit from customer complaints? Journal of Business Research, 69(2), 944-955. doi:10.1016/j.jbusres.2015.08.038

Yu, Y., Duan, W., \& Cao, Q. (2013). The impact of social and conventional media on firm equity value: A sentiment analysis approach. Decision Support Systems, 55(4), 919-926. doi:10.1016/j.dss.2012.12.028 
Ming Chen, First author, is currently a lecturer in the School of Marketing and Logistics Management at Nanjing University of Finance and Economics, China, working in the field of marketing. He holds a Ph.D. in Business Administration (major: Marketing) from National Central University, Taiwan in 2018 and a M.S. degree in Business Administration (major: Hospitality and international tourism) from Griffith University, Australia in 2014. His main research fields include consumer behavior, consumer psychology, advertising, e-commerce. He has published more than 10 Journal and conference articles. Journals where his research has been published include the Current Psychology, Electronic Commerce Research, and Frontiers in Psychology.

Yidan Huang, Corresponding Author, lecturer of marketing at Economics and Business Department at the HuaQiao University, China. Her recent research interests in Consumer behavior, Design Service, Computer-mediated communication.

Shih-Heng Yu is an Assistant Professor at the Department of Business Management of National United University, Taiwan. He holds a Ph.D. degree in Business Administration from National Central University. His main areas of research include E-commerce, benchmarking and performance evaluation, sustainable operations management, and decision analysis. Journals where his research work has been published include Electronic Commerce Research and Applications, Social Indicators Research, and International Journal of Environmental Research and Public Health.

Chia-Huei Wu (PhD), Corresponding Author, is currently an Assistant Professor at Institute of Service Industries and Management, Minghsin University of Science Technology in Taiwan. She received Ph.D. degree in Technology Management from University of Chung Hua. Dr. Wu has well over 30 published peer-reviewed journal articles. Her recent research interests in Service Management, Marketing Management, Consumer Behavior and E-commerce. She is serving on the editorial boards of some journals. 